\title{
O TEMA DAS DESIGUALDADES EDUCACIONAIS NO CONTEXTO PÓS SEGUNDA GUERRA MUNDIAL
}

Rodrigo Oliveira Lessa ${ }^{1}$

\begin{abstract}
RESUMO: Neste estudo buscamos trazer um panorama sobre algumas das mais relevantes pesquisas e reflexões sobre o tema da educação no âmbito da teoria sociológica no contexto pós Segunda Guerra Mundial. Por meio deste levantamento, analisamos de que maneira esta produção respondeu aos desafios lançados pelas contradições envolvendo os movimentos de expansão e retração do ensino básico e universitário, bem como o combate e a reprodução das desigualdades sociais envolvendo os processos educacionais. São revisitadas as ideias e questões fundamentais trazidas pelos os surveys e pesquisas quantitativas que revelaram a fragilidade projeto de uso da educação como instrumento de promoção da ascensão econômica da classe trabalhadora, como o Relatório Coleman (1966) e as produções do Institut National d'Études Démografiques (INED), além das teorias da reprodução de Pierre Bourdieu e Louis Althusser, que problematizaram os conhecimentos e práticas escolares fenômenos de manutenção e reprodução de desigualdades.
\end{abstract}

Palavras-chave: Sociologia da Educação. Desigualdades sociais. Segunda Guerra Mundial.

\section{THE THEME OF EDUCATIONAL INEQUALITIES AFTER THE WORLD WAR II}

\begin{abstract}
In this study we seek to provide an overview of some of the most relevant research and reflections on the subject of education in the context of sociological theory in the post WWII context. Through this survey, we analyze how this production responded to the challenges posed by the contradictions involving the expansion and retraction movements of basic and university education, as well as the combat and reproduction of social inequalities involving the educational processes. It revisits the ideas and fundamental questions brought by the surveys and quantitative research that revealed the fragility of the project of using education as an instrument to promote the economic rise of the working class, such as the Coleman Report (1966) and the productions of the Institut National d'Études Démografiques (INED), in addition to the reproduction theories of Pierre Bourdieu and Louis Althusser, who problematized the school knowledge and practices, phenomena of maintenance and reproduction of inequalities.
\end{abstract}

Key-words: Sociology of Education. Social inequalities. World War II.

\section{INTRODUÇÃO}

\footnotetext{
${ }^{1}$ Doutor em Ciências Sociais pela Universidade Federal da Bahia - UFBA. Membro do Núcleo de Estudos Ambientais e Rurais - NUCLEAR, com sede na Faculdade de Filosofia e Ciências Humanas - FFCH da UFBA. Professor EBTT do Instituto Federal de Educação, Ciência e Tecnologia Baiano - IF Baiano. Autor do livro O Conflito Social no Campo no Cinema Documentário Brasileiro: luta de classes e representação fílmica (2016) e um dos organizadores de Cinema Documentário Brasileiro em Perspectiva (2013). Contato: rodrigo.ciso@gmail.com
} 
Como observa Maria Alice Nogueira (1999) em A Sociologia da Educação do Final dos Anos 60/Início dos Anos 70: o nascimento do paradigma da reprodução, as décadas de 1950 e 1960 e contexto do pós-guerra presenciaram um período de convergência entre uma fase de grande crescimento econômico e emergência de um ideário de igualdade nos países desenvolvidos. Neste período, países como França e Inglaterra protagonizaram não só uma ampliação nunca antes vista de seus aparelhos escolares, dedicada a dar conta da qualificação da mão-de obra, como também promoveram discussões importantes sobre o seu papel para a redução das desigualdades sociais no mundo capitalista, sobretudo quando os programas de educação compensatória, até então vistos como fiéis promotores da igualdade, começaram a ser criticados como mecanismos de reprodução de diferenças e manutenção da imobilidade social.

Dentro deste contexto, é possível destacar, segundo autora, a emergência de dois campos teóricos importantes. De um lado, (a) os grandes levantamentos estatísticos ou surveys desenvolvidos sobretudo nos EUA e nos países anglo-saxões, que revelaram contradições na perspectiva de utilização das instituições escolares como meios seguros e eficientes de redução das desigualdades sociais em famílias pobres das grandes cidades. De outro, (b) o paradigma da reprodução, que, emergindo na França, não só ofereceu uma matriz explicativa macrosociológica para as polêmicas lançadas pelos surveys como apontou os fenômenos relativos aos processos de reprodução do conhecimento escolar como ponto de partida para a compreensão do modo como as desigualdades sociais se reproduziam também dentro das instituições escolares. Deste modo, sem pretensão de esgotar as temáticas ou autores, abordaremos os principais trabalhos de cada uma destas reflexões sobre o tema das desigualdades sociais no contexto do pós-guerra, de modo a dar um panorama sobre o tema das desigualdades educacionais no contexto do pós-guerra e os debates desenvolvidos em torno dele no âmbito da Sociologia.

\section{CONTEXTO SOCIAL E HISTÓRICO DO PENSAMENTO SOCIAL SOBRE A EDUCAÇÃO NO PÓS GUERRA}

O contexto social e histórico dos debates sobre as desigualdades educacionais no pósguerra envolve uma série de mudanças políticas, econômicas e sociais em geral vivenciadas em meio à retomada do crescimento econômico e à reconstrução dos países envolvidos nos conflitos mundiais. No entanto, três elementos são particularmente importantes dentro deste contexto. 
Em primeiro lugar, alguns anos após as crises e períodos de carência provocados pelos conflitos que se encerraram em 1945, os países desenvolvidos do ocidente entraram num período de grande prosperidade e crescimento econômico, o qual só sofreria um novo momento de inflexão por volta dos anos 1970. Dentre os resultados mais concretos deste estado de properidade, então conhecido como "Les 30 gloriouses" pelos franceses, vale destacar primeiramente a montagem de grandes aparatos estatais de serviço e proteção social, englobados mais tarde pelo aquilo se se convencionou chamar de welfare state ou étatprovidence.

O princípio dominante destes aparatos burocráticos, dentro do contexto em que foram criados, era o de promoção da igualdade social através da luta contra as desigualdades. A implantação deste projeto, por sua vez, inspirou todo um conjunto de abrangentes políticas de combate à probreza, programas de reforma social e, sobretudo, políticas de desenvolvimento econômico e modernização tecnológica, que colocaram na ordem do dia o problema da mãode-obra qualificada e de sua formação adequada para as funções que estavam sendo criadas nas mais diversas áreas do conhecimento. Neste sentido, a formação de quadros adminstrativos, burocráticos, técnicos e científicos vinha junto com uma grande preocupação em buscar e preparar recursos humanos capazes de manter em marcha as perspectivas de crescimento econômico e político das grandes nações do mundo desenvolvido.

Em segundo, como também nota Eric Hobsbawm (1995) em A Era dos Extremos, a retomada da natalidade anterior à guerra a partir de 1946 ocorreu concomitante a um período de grande crescimento demográfico. Algo que, por sua vez, não só tensionou ainda mais os debates sobre as políticas de igualdade como tornou a demanda pelo ensino primário uma complexa e ampla tarefa a ser executada pelos aparatos estatais do estado de bem-estar social do pós-guerra. De um lado, no que diz respeito aos sistemas educacionais, houve um rápido e substancial crescimento dos efetivos escolares, acompanhados de um financiamento dos gastos púbicos para permitir a instrução destes contingentes. De outro, se iniciou toda uma fase de aquecimento dos conflitos políticos e debates sociais colocados pelas diversas minoriais que se sentiam de alguma maneira restringidas em sua busca pelos direitos sociais que começavam a ser reconhecidos pelo Estado. Algo que suscitou a toda uma onda de mobilizações e lutas sociais que passaram a questionar os termos em que estes aparatos estatais vinham se mantendo acessíveis à população e a não contemplação do princípio de promoção da igualdade em que haviam sido formulados.

Assim, diante do contexto de explosão demográfica, pressão dos setores produtivos por mão-de-obra das demandas no âmbito da sociedade civil, como sinaliza Maria Alice 
Nogueira (1990), se configurou todo um contexto de ampliação do aparelho escolar e universalização do ensino secundário, harmonizado com os ideais de igualdade do Estado de bem-star social e projetado para atender às demandas que surgiam com a explosão demográfica. O qual, por sua vez, veio acompanhado de uma série de problemas e tarefas se colocaram para o poder público, que precisava dentre outras coisas produzir um plano de recrutamento de alunos e professores e definir critérios para delimitar os conteúdos e processos de ensino. A adminstração das grandes máquinas burocráticas em que se transformavam os sistemas de ensino demandavam um maior conhecimento da população escolar a respeito do seu funcionamento e operacionalidade efetivos - condição inclusive para que o planejamento pudesse ser eficientemente executado - e desta maneira multiplicaram-se tanto as vias de financiamento para a pesquisa educacional quanto o número de profissionais e intelectuais de diversas formações dedicadas ao estudo dos temas relativos a estes sistemas.

Por último, no âmbito da produção intelectual, jutamente com o período de grande prosperidade econômica, os anos 1950-60 conviveram também com uma importante fase de desenvolvimento no campo das Ciências Sociais e da Sociologia em particular. De um lado, o pensamento social alcançou um avanço sem precedentes na história, sobretudo a partir da conjuntura de penetração dos Estados nacionais sobre as Ciências Sociais e, ademais, por meio da criação de instituições sociais de âmbito internacional dedicadas ao estudo e transformação da realidade humana no pós-guerra, como a UNESCO (Organização das Nações Unidas para a Educação, a Ciências e a Cultura) e a OCDE (Organização Para a Cooperação e Desenvolvimento Econômico). De outro, também por influência destas instâncias oficiais, o tema da mudança social ou da mutação da sociedade em vias de modernização terminou se confirmando como a principal preocupação da produção sociológica, desafiada a responder às indagações que se colocavam em uma sociedade em vias de transformação e reconstrução, diante dos conflitos e crises recentes.

Todavia, com a crise da ideologia modernizadora que o período de guerras provocou, este avanço da produção no campo das Ciências Sociais não significou necessariamente otimismo. A nova fase que se abriu na paisagem sociológica, sobretudo com o final do ciclo de crescimento dos países desenvolvidos, foi a da chamada por Alain Tourraine (1986) em $O$ Estado das Ciências Sociais na França de "Era da Suspeita".

Neste período, predominou o desencanto deixado pelas lacunas e fracassos das reformas sociais liberais dos anos 1960 e a ideia emergente de que o homem não seria verdadeiramente o sujeito de sua própria ação e vontade, mas sim um produto das etruturas sociais que o determinariam. Para essa Sociologia, a vida social não seria sinônimo de projeto, 
debate, criação e conflito, mas sim discurso, mecanismos de inclulcação e legitimação do poder, marcados sobretudo pela força da ideologia burguesa e das relações de poder dominantes. Ao propagar-se ao ponto de se tornar o pensamento dominante no decorrer dos anos 1970, esta forma de compreender e representar o funcionamento social atingiu de modo mais incisivo três áreas do pensamento social: a sociologia urbana, a sociologia do ator ou da ação e, por último, a sociologia da escola.

\section{PESQUISAS QUANTITATIVAS E REPERCUSSÃO POLÊMICA}

Neste contexto, pesquisas sobre os chamados "programas de educação compensatória" ganharam bastante relevo. No quadro da guerra contra a pobreza, pretendia-se corrigir as desigualdades escolares mediante a implantação de medidas assistenciais e pedagógicas visando compensar desvantagens materiais enfrentadas pelos grupos socialmente desfavorecidos, como também as supostas carências culturais resultantes de um ambiente familiar pouco estimulante. Aqui, estudos como os realizados no âmbito da London School of Economics, na Inglaterra, o Head Start (1965) e o Relatório Coleman (1966), nos Estados Unidos, além das pesquisas de Paul Clerc e Alain Girard no Ambito do Instituto Nacional de Estudos Demográficos - INED, na França, tiveram grande importância em meio a estas avaliações.

Os resultados, contudo, revelaram algo em certo sentido inesperado no campo da pesquisa sobre a universalização da educação para a época. Diferentemente do que imaginavam os profissionais de formação humanista e funcionalista que refletiam sobre a educação, muito influenciados pelos paradigmas lançados por Émile Durkheim e Talcott Parsons, os sistemas escolas não só não tinham o efeito esperado na redução das desigualdades sociais como, longe de serem sítios de igualdade, terminavam reproduzindo as desigualdades sociais que existiam no âmbito da sociedade de classes.

\section{O RELATÓRIO COLEMAN (1966)}

O Relatório Coleman é um dos principais marcos deste momento. No ano de 1966, em pleno contexto das lutas pelos direitos civis nos EUA, o Congresso Nacional deste país publicou os resultados do que foi chamado na época de "Missão Coleman”. Neste estudo, o então sociólogo James Coleman da Universidade de Chicago e uma equipe chefiada por ele obteve um grupo de resultados bastante polêmicos a partir de um complexo e inovador 
levantamento estatístico. Em Equality of Education Opportunity (1966), Coleman e seus colaboradores chegaram a conclusão que as escolas, naquele período, tinham pouquíssima influência no apoio a jovens que buscassem melhores condições de vida, sendo, portanto, a instituição escolar um recurso que teria pouca capacidade de transformação ou minimização das desigualdades sociais vivenciadas pelos grupos que buscavam-na como instrumento para a ascensão social. Ao perceber que a variabilidade da condição socieconômica dos estudantes é maior no interior das escolas, entre os estudantes de origens diferentes, do que entre as escolas, Coleman pôde mostrar que as diferenças de resultados no levantamento da desigualdade nas instituições se deviam mais às diferenças da clientela das escolas - a origem dos estudantes, a condição de suas famílias - do que às diferenças entre as características escolares - dado à presença ou não de recursos, equipamentos, programas de qualificação de professores, etc. Deste modo, ao minimizar o efeito do emprego de recursos e investimentos na escola como meio de combate às diferenças sociais, o estudo representou uma crítica contundente às tendências e segmentos políticos que atribuíam ao investimento em educação um caminho seguro para a redução das desigualdades.

Como analisa Silvio Higgins (2005) em Quarenta Anos do Relatório Coleman, ao notar que é sobretudo no ambiente, no lar e na região onde vivem os estudantes que se mostra uma correlação mais clara entre desigualdades sociais e restrição à educação formal, Coleman também passa a buscar na diferenciação e explicação das formas de capital social que estão presentes na vida dos jovens um meio de destacar situações que de fato se mostram relevantes para os resultados do seu desempenho e acesso à educação. Neste sentido, na obra The Social Capital in the Creation of Human Capital (1988), Coleman diferencia entre os componentes familiares (a) o capital financeiro da família, mensurado em termos de renda, (b) o capital humano, obtido a partir da escolaridade dos pais, e por fim (c) o capital social que se expressa na intensidade das relações intrafamiliares, tendo cada um destes elementos uma importância particular. Os quais, por sua vez, teriam muito mais importância na investigação e na problematização da relação entre desigualdades sociais e ambiente escolar.

\section{AS PRODUÇÕES DO INSTITUT NATIONAL D'ÉTUDES DÉMOGRAFIQUES - INED}

Na França, estas práticas dominantes de estudos empíricos na Sociologia assumiram a forma de uma demografia escolar, que tem origem nos trabalhos desenvolvidos pelo Institut National d'Études Démografiques - INED, criado em 1945 sob a direção de Alfred Sauvy. Tarefas como o recenseamento da população escolarizada e a investigação das características 
e evolução das populações escolares foram assumidas pelo instituto e pelos profissionais que trabalharam em sua colaboração, como Henri Bastide, Alain Girard e Paul Clerc, objetivandose conhecer as condições de seleção e frequência ao sistema escolar, bem como os mecanismos de orientação no seu interior. Destaca-se, neste sentido, o famoso estudo da Enquête de 1962-72, quando através de uma grande amostra que contou com mais de 17.000 alunos se acompanhou o itinerário no interior do sistema escolar de um conjunto de indivíduos durante dez anos.

Todavia, como nos informa Chistian Baudelot em Todo se sabe y nada se cambia (2010), no estudo em que se analisaram as condições de ingresso na etapa do sixième ou sexto grau escolar na França ainda nos anos 1960, Girard e Bastide tiveram o mérito e inaugurar uma nova era de análises sociológicas sobre a realidade escolar e sua relação com as funções sociais reais que esta mantinha no universo francês. Os resultados, publicados sob o título de La stratification sociale et la démocratisation de l'enseignement, em 1963, promoveu sobretudo duas contribuições importantes, que mudariam de forma substancial o modo pelo qual a educação formal era compreendida e estudada no país. Em primeiro lugar, Bastide e Girard criaram um um banco de dados nacional de grande amplitude e qualidade, cruzando dados como idade, sexo, profissão dos pais dos alunos, obtenção de trabalo pelos egressos de êxito escolar. Em segundo, eles promoveram, na análise dos dados, uma descoberta extremamente relevante: a de que as desigualdades frente à escola não se explicavam pelas diferenças entre os ingressos nas famílias, mas sim pela brecha de nível de instrução entre os pais.

A pesquisa levou estudiosos como Paul Clerc, Jean-Claude Passeron e Pierre Bourdieu a iniciar, na França, uma nova forma de lidar com as recentes descobertas relativas às desigualdades sociais no âmbito da escola. A qual, por sua vez, teve como traço particular a proposição de que estaria na autonomia do capital cultural e nos fenômenos relativos aos processos de reprodução do conhecimento escolar o caminho para pensar a presença das desigualdades sociais no âmbito da escola. Os conteúdos e as formas de pensamento presentes e reproduzidas na escola deixariam, a partir dali, de serem questões relegadas a segundo plano, como elementos neutros ou meras ferramentas abstratas. Os conhecimentos e práticas escolares passavam a ser a partir de então problematizados como verdadeiros fenômenos de manutenção e reprodução de desigualdades dentro de uma instituição sobre a qual se depositava muita esperança mas poucas suspeitas até meados dos anos 1960.

\section{O PARADIMA DA REPRODUÇÃO}


O debate internacional e a pesquisa de Girard e Bastide levaram uma série de estudiosos a iniciar - sobretudo na França - uma série de discussões destinadas a buscar uma nova forma de lidar com as recentes descobertas relativas às desigualdades sociais no âmbito da escola. A qual, por sua vez, como observa Baudelot (2010), teve como traço particular a proposição de que estaria sobretudo nos fenômenos relativos aos processos de reprodução do conhecimento escolar o caminho para pensar a presença das desigualdades sociais no âmbito da escola. Foi através deste pressuposto que, nos anos seguintes, com contribuições e perspectivas de matrizes teóricas distintas, autores como Louis Althuser, Pierre Bourdieu, Jean-Claude Passeron, Basil Bernstein, Samuel Bowles e Herbert Gintis deram importantes contribuições para o que ficaria conhecido anos mais tarde como o "paradigma da reprodução". Com a contribuição deste autores, os conteúdos e as formas de pensamento presentes e reproduzidas na escola deixariam de ser questões relegadas a segundo plano, como elementos neutros ou meras ferramentas abstratas.

Como observa Henry Giroux (2004) em Teoría e Reistencia en Educación, é possível distinguir duas posições principais que emergem da ampla gama de abordagens reproducionistas e de teóricos que contribuíram com estas discussões. De um lado, as "teorias da reprodução social", que têm seu exemplo mais representativo no trabalho de Louis Althusser, mas contam também com as importantes asserções de Samuel Bowles e Herbert Gintis. E, de outro, temos as "teorias da reprodução cultural", onde podemos situar aqueles que talvez sejam os principais nomes nesta linha investigativa, Pierre Bourdieu e Jean-Claude Passeron, seguidos por Basil Bernstein e suas discussões no âmbito da teoria da transmissão da cultura. Como nosso objetivo aqui é sobretudo destacar a produção mais próxima do contexto do pós-guerra, destacaremos como Bourdieu e Passeron, de um lado, e Louis Althusser, de outro, conduziram as primeiras explicações no âmbito do paradigma da reprodução diante dos dados e polêmicas que surgiram com os surveys nos EUA e na França.

\section{BOURDIEU E O ESTUDO DA EDUCAÇÃO FRANCESA}

A contribuição de Bourdieu pode ser encontrada nas realizações em parceria com Jean-Claude Passeron, nas quais a educação é o tema ou um dos temas centrais da discussão, como em Os Herdeiros (2013), A Reprodução (2008) e A Miséria do Mundo (1997), mas também nos desdobramentos de alguns de seus principais conceitos, como capital social e habitus. No entanto, como observam Maria Alice Nogueira e Claudio Marques Nogueira 
(2002) em A Sociologia da Educação de Pierre Bourdieu, esta obra pode ser compreendida a partir de duas dimensões fundamentais: de um lado, a configuração desigual da escola e o seu papel para a reprodução de desigualdades sociais e, em segundo, as reflexões sobre o tema da constituição diferenciada dos atores segundo a sua origem social e familiar e as repercussões dessa formação diferenciada para sua vida escolar.

Quando Bourdieu menciona, no prefácio de A Reprodução (2008), que existe um princípio de inteligibilidade que orienta vários capítulos do livro, o que envolve as relações entre o "sistema de ensino" e a "estrutura das relações entre as classes", a noção de arbitrário cultural emerge em sua obra como um ponto de partida fundamental. Isso porque, como não existe nenhuma cultura superior a outra, a adoção de um tipo específico de cultura a ser consagrada e transmitida pela escola como sendo superior e universal é analisada por ele como que se deve não à sua verdade objetiva, mas sobretudo ao modo como reproduz e legitima a dominação de classe.

No entanto, apesar de arbitrária, a cultura escolar se apresenta e é reconhecida socialmente como a cultura legítima, a única universalmente válida. Esta conversão de um arbitrário cultural em uma cultura legítima, por sua vez, é uma prerrogativa que legitima a violência simbólica ou imposição de um conhecimento arbitrário por meio da dissimulação deste caráter, sendo ela, portanto, uma das condições sociais fundamentais da ação pedagógica da escola. Por isso, esta só pode ser compreendida quando se considera a dinâmica da relação entre os vários arbitrários em disputa em uma determinada sociedade, bem como as relações de força entre os grupos ou classes sociais presentes nessa mesma sociedade.

Por conseguinte, é também por este caminho que, na relação de comunicação pedagógica (ensino), se reproduzem e se legitimam as desigualdades sociais: a relação se apresenta como pautada num valor de equidade que, no entanto, é apenas formalmente igualitária, e desse modo as diferenças de classe que existem no âmbito da realidade social, fora o sistema de ensino, se condicionam também o seu funcionamento.

O argumento central desta discussão, portanto, é o de que ao dissimular que sua cultura é a cultura das classes dominantes, o sistema escolar dissimula igualmente os efeitos que este fator mantém para com o sucesso escolar das classes dominantes e, ao mesmo tempo, das dominadas. Estas diferenças, que são oriundas sobretudo de desigualdades sociais, transformam-se em desigualdades educacionais ao serem percebidas como diferenças de capacidade entre indivíduos com iguais condições de acesso ao conhecimento e à formação culta. Enquanto elas decorrem da maior ou menor proximidade entre a cultura escolar e a 
cultura familiar que o aluno enfrenta nestas instituições, a doutrina do dom é reproduzida como a justifica que individualiza e descontextualiza o caráter socialmente condicionado destas diferenças de rendimento e carreira na vida escolar. (NOGUEIRA, 1999).

Sinteticamente, portanto, é possível dizer que as reflexões do autor sobre a escola partem da constatação de uma correlação entre as desigualdades sociais e as escolares que é ocultada por uma arbitrária transformação da cultura escolar dominante em uma cultura universalmente válida, legítima e neutra por natureza. Isso fica claro, por exemplo, na sua análise dos currículos, dos métodos pedagógicos e da avaliação escolar, onde nota que os conteúdos curriculares são selecionados em função dos conhecimentos, nos valores e interesses das classes dominantes, onde prestígio de cada disciplina é associado a sua maior ou menor afinidade com as habilidades valorizadas pela elite cultural, na sua análise sobre a transmissão dos conhecimentos, que segue uma espécie de "cultura do implícito" onde a pedagogia supõe e exige a posse de um capital cultural anterior, e, por último, na avaliação dos professores, que vai muito além de uma verificação do aprendizado e se estende a um verdadeiro julgamento social em relação ao alinhamento ou não diante dos comportamentos das classes dominantes.

Como nota Maria Alice Nogueira (1999), a sociologia de Bourdieu como um todo está marcada pela busca da superação de um dos dilemas clássicos da teoria social: a que se define pela oposição entre objetivismo e subjetivismo. Como forma de distanciamento em relação ao objetivismo - apontados por ele como uma marca inerente muitas vezes ao estruturalismo e ao marxismo -, Bourdieu adianta que a ação das estruturas sociais sobre o comportamento individual se daria preponderantemente de dentro para fora, e não o inverso.

Deste modo, no que diz respeito ao objetivismo e à ação dos atores sociais envolvidos com os sistemas escolares, a formação inicial e o ambiente social e familiar corresponderia na verdade a uma posição específica na estrutura social, como vemos já relativamente delineado na obra Os Herdeiros (2013). Nestas estruturas, adquiridas sobretudo em meio ao ambiente familiar, os indivíduos incorporariam um conjunto de disposições para uma ação típica dessa posição que, por sua vez, passaria a conduzi-los ao longo do tempo e nos mais diversos ambientes de ação. As normas, regras e constrangimentos que seriam responsáveis pela reprodução destas estruturas não estariam, deste modo, definidas como entidades reificadas que agem diretamente: a estrutura social se perpetuaria justamente porque os próprios indivíduos tenderiam a atualizá-la ao agir de acordo com um conjunto de princípios e disposições formulados e compartilhados a partir da posição estrutural para a qual eles foram socializados. Estas disposições incorporadas pelo sujeito, desse modo, não o conduzem em 
suas ações de modo mecânico: elas não consistiriam em normas rígidas e detalhadas de ação, mas sim em princípios de orientação que precisariam ser adaptados pelo sujeito às variadas circunstâncias.

Por outro lado, quanto à postura subjetivista, Bourdieu salienta que o ator social não pode ser concebido como um indivíduo isolado, consciente, reflexivo, nem o sujeito determinado, mecanicamente submetido às condições objetivas em que ele age. Ele nega neste sentido o caráter supostamente autônomo do sujeito individual para mostrar que os indivíduos precisam ser caracterizados por uma bagagem socialmente herdada. Bagagem esta que inclui, de uma parte, certos componentes objetivos e externos ao indivíduo, e que por isso podem ser postos à serviço do sucesso escolar. Neste sentido, como explicita em $A$ Reprodução (2008) a relação pedagógica não pode ser interpretada como uma simples relação de comunicação mais ou menos eficiente entre estes sujeitos independentes. É necessário contextualizá-la através do processo de seleção diferencial segundo a origem social e as variações de competência linguística em função da classe social de origem dos estudantes, e nesta medida examinar a relação entre a origens sociais destes estudantes e os graus de êxito de sua empreitada no sistema escolar.

Para integrar numa conceituação o rol de componentes objetivos e subjetivos, Bourdieu (2008) utiliza o conceito de "capital". Ele representa um poder capaz de definir as probabilidades de ganho num determinado campo social, podendo existir na forma de um capital econômico, tomado em termos de bens e serviços a que os estudantes têm acesso, de capital social, que indica o conjunto de relacionamentos sociais influentes mantidos pela família, e por fim de capital cultural, formado pelo conjunto de conhecimentos e noções que o indivíduo incorpora e é capaz de acionar no campo social. Este capital cultural, vale observar, é justamente o que teria maior impacto na definição do destino escolar, podendo aparecer no (a) estado incorporado, na forma de disposições duráveis do organismo, (b) no estado objetivado, sob a forma de bens culturais, transmissíveis de maneira instantânea, e (c) no estado institucionalizado, quando se manifesta basicamente através dos diplomas e títulos escolares. (NOGUEIRA, 1999).

Neste sentido, como aponta Bourdieu, a posse de capital cultural facilitaria a aprendizagem dos conteúdos e códigos escolares, sobretudo na medida em que aqueles conhecimentos considerados legítimos (cultos, apropriados, sofisticados) permitiriam a passagem do mundo familiar ao universo escolar. Para as crianças oriundas de meios culturalmente favorecidos, o ingresso na educação formal seria mais facilmente uma continuação da educação familiar, enquanto para as outras significaria algo estranho, distante, 
ameaçador. Em segundo, a posse de um determinado capital cultural propiciaria um melhor desempenho nos processos formais e informais de avaliação. Como os sistemas de medição do rendimento escolar vão muito além de uma simples verificação de aprendizagem, incluindo um verdadeiro julgamento cultural ou até mesmo moral dos alunos, bastante específico, estas exigências só são plenamente atendidas por quem foi previamente socializado nesses mesmos valores. Por último, vale ressaltar que, ainda no que diz respeito ao capital cultural, a informação sobre a estrutura e o funcionamento do sistema de ensino influi sobre a compreensão da dinâmica das hierarquias e ramificações acadêmicas por parte das famílias e também dos alunos. Esta compreensão, que inclui as possibilidades de alcance de prestígio social e retorno financeiro, orientam o modo pelo qual os pais e responsáveis pelas crianças poderão avaliar as estratégias de formação de seus protegidos e tomar decisões cruciais para a vida dos estudantes - o que pode influenciar na continuação ou interrupção de estudos, mudança de estabelecimento, escolha de curso superior, etc.

Quanto à transmissão ou reprodução destas práticas, estratégias, escolhas e comportamentos no âmbito dos grupos familiares, Bourdieu (2008) salienta que cada grupo social, em função das condições objetivas que caracterizam sua posição na estrutura social, termina constituindo e sendo por sua vez também orientado por um sistema específico de disposições para a ação, passado adiante na forma de habitus. Pelo acúmulo histórico de experiências de êxito e fracasso, estes grupos construiriam um conhecimento prático relativo ao que seria possível ou não de ser alcançado pelos seus membros dentro da realidade social cotidiana, como também sobre as formas mais adequadas de fazê-lo. O habitus nestas circunstâncias, portanto, seria mais precisamente o conhecimento ou conjunto de conhecimentos adquiridos que se ajustam às estratégias de aquisição ou aumento do capital referente ao campo ou espaço social em questão, fornecendo as estratégias mais adequadas, viáveis e possivelmente eficientes que acabariam sendo adotadas pelos grupos. O que, por sua vez, as tornaria também fator estruturante de novas ações e estruturas sociais socialmente compartilhadas, na medida em que fossem incorporadas pelos sujeitos e, deste modo, se tornassem elas também habitus estruturantes capazes de condicionar o comportamento das gerações futuras.

Como observa Bourdieu já em Os Herdeiros (2013), o fenômeno poderia ser mais claramente percebido através das estratégias de investimento escolar e comportamentos distintos que podem ser notados nas principais classes sociais na realidade social. Nas classes populares, por exemplo, pobre em capital econômico e cultural, nota-se um investimento moderado no sistema de ensino. O que, por sua vez, ocorre por haver ali a percepção de que 
as chances de sucesso são reduzidas e pela escassez de recursos econômicos sociais capazes de potencializar o valor dos títulos alcançados ou almejados, fazendo com que o investimento no mercado escolar tenda a oferecer um retorno baixo e incerto à longo prazo e esta realidade, por sua vez, diminua a própria iniciativa destes grupos em buscar reverter ou desafiar esta lógica.

Nas classes médias, por sua vez, esta configuração se dá de maneira distinta. Estas tenderiam a investir pesada e sistematicamente na escolarização dos filhos, sobretudo por terem chances objetivamente superiores de sucesso - o que é percebido e incorporado a longo prazo - e nutrir, diante destas possibilidades, expectativas mais recorrentes de ascensão social, agora em direção às elites. Além de, justamente em função desta expectativa, valorizar de maneira enfática o valor da cultura legítima, o que termina fazendo da sua aquisição um esforço sistemático dentro destes grupos sociais.

Já entre as elites econômicas e culturais, o que se percebe mais claramente é um investimento também incisivo na educação escolar, mas de uma maneira menos pragmática do que nas classes médias. Sobretudo pelo fato de que o sucesso escolar no caso destas famílias ser tido como natural, não dependendo de um grande esforço de mobilização familiar, estas elites estariam livres da luta pela ascensão social, ficando a sua dinâmica de investimento na escolarização determinada pelo tipo de elite que elas constituem na realidade social. No caso das elites culturais, haveria um investimento intenso, mas sobretudo visando o acesso a carreiras mais longas e prestigiosas do sistema de ensino. Já entre as frações das elites econômicas, vigoraria a busca pela certificação que legitimaria o acesso a posições de controle já garantidas pelo capital econômico.

\section{LOUIS ALTHUSSER E A PROBLEMÁTICA DOS APARELHOS IDEOLÓGICOS DE ESTADO}

Outro autor que se preocupou com a relação entre a realidade social e a reprodução da desigualdade e da ideologia pela instituição escolar foi Louis Althusser. Como observa em Aparelhos Ideológicos de Estado (1983), a escolarização em uma sociedade capitalista teria um duplo papel: a reprodução da força de trabalho necessária para a acumulação de capital e, em segundo, a reprodução de formas de consciência, disposições e valores necessários para a manutenção de instituições e relações sociais que facilitem a conversão de trabalho em capital. Sob um referencial epistemológico marcadamente marxista, mas também estruturalista, Althusser toma a escola na sociedade capitalista como o principal elemento 
reprodutor da ideologia dominante, sendo ela a principal instituição daquilo que ele denomina de "aparelhos ideológicos de Estado". O que por sua vez significa mais precisamente um conjunto de realidades que opera no universo privado e que, junto com o aparelho repressivo de estado, com atuação preponderantemente pública, tem papel fundamental na reprodução da força de trabalho como um fator submisso à dominação de classe.

Como apresenta Althusser (1983), a condição última da produção é mais exatamente a reprodução das condições de produção, que deve atuar tanto sob as forças produtivas quanto sob as relações de produção existentes. Esta reprodução, no entanto, não deve ser buscada ao nível mais imediato, na empresa capitalista ou no processo de produção propriamente dito, pois não é neste nível que a reprodução das condições materiais existe em suas condições reais, atuando sob estes dois elementos. E isso por um motivo relativamente simples: um dos elementos principais desta reprodução, aquele que separa as forças produtivas dos meios de produção, a força de trabalho, se dá fora da empresa, no âmbito da vida social.

Neste âmbito, como observa José Augusto Albuquerque (1983) em Althusser, As Ideologias e As Instituições, a reprodução da força de trabalho não exige somente uma reprodução de sua qualificação. Ela precisa também da reprodução da submissão deste fator humano às normas da ordem vigente. Isto é, a reprodução depende da submissão dos operários à ideologia dominante, de modo que esta assegure também, por meio do pensamento, o seu predomínio sobre os indivíduos. Como este papel é, por sua vez, assumido por instituições como o Estado, a igreja e a escola, são elas que fornecem o modo de agir e os conhecimentos sob formas que assegurem a dominação à ideologia e ao domínio de sua prática. Razão pela qual, ademais, é na complexidade e particularidade da superestrutura que Althusser buscará entender os termos de sua reprodução.

Na tradição marxista, como indica Althusser (1983), o Estado é, antes de mais nada, o principal aparelho da superestrutura. $\mathrm{Na}$ sua objetividade, ele compreende tanto o conjunto dos aparelhos especializados - como os tribunais, as prisões, a política, etc. - quanto o exército ou o conjunto das forças de repressão e, por último, e acima de todos, a chefia de Estado, sendo esta representada pelo governo ou pela administração de um modo geral.

Mas como esta concepção permanece, aos olhos do autor, basicamente descritiva, sua análise sobre os aparelhos ideológicos que compõem o Estado buscam justamente analisar e dar maior concreticidade a ela. Segundo Althusser, O Estado, além de ser aparelho de Estado e aparelho repressivo de Estado, é também o lócus de um poder do Estado, responsável por conduzir e operar este aparelho e, por último, o conjunto dos aparelhos ideológicos de Estado, responsáveis por manter e reproduzir a submissão à classe dominante. 
Os aparelhos ideológicos de Estado são, portanto, em última instância, um certo número de situações que se apresentam ao observador imediato sob a forma de instituições distintas e especializadas, que podem se ver representadas em organismos como: os AIE religioso, escolar (escolas públicas e privadas), familiar, sindical, jurídico, político, cultural e de informação. Por isso, se na concepção inicial observamos a existência de um aparelho essencialmente repressivo de estado, numa descrição mais analítica é possível perceber que há, na verdade, uma pluralidade de aparelhos ideológicos de Estado responsáveis por garantir, no âmbito da superestrutura, a reprodução da cultura, das formas de pensar e das relações sociais originárias da classe dominante.

Nota-se, portanto, uma diferença fundamental entre aquilo que compreende o aparelho de Estado propriamente dito, que é predominantemente público, e os aparelhos ideológicos de Estado, que são basicamente privados. Contudo, ao lado desta diferença, existe outra, ainda mais importante: enquanto o primeiro age sobretudo por meio da violência e da detenção do seu monopólio legítimo, o conjunto que compõe o segundo opera sobretudo por meio da ideologia, dos saberes. O que unifica os dois, apesar das diferenças, é o seu funcionamento mesmo, reproduzindo do mesmo modo a ideologia. Contudo, isto não afasta a diferença de recorrer basicamente ao uso da força para impor a sua ordem, no que diz respeito ao aparelho repressivo, e à ideologia, no segundo.

No que diz respeito à reprodução das relações de produção, segundo elemento fundamental da reprodução das condições de produção, é possível para Althusser (1983) perceber que esta se pauta numa espécie de divisão social do trabalho, onde historicamente um ou outro aparelho ideológico de Estado assume uma posição fundamental na reprodução da submissão à classe dominante. Neste sentido, se, no caso do feudalismo, foi a religião que assumiu este papel, o que pode ser notado pelo caráter da ação dos aparelhos inquisitórios e da necessidade de emancipação do seu controle pela burguesia durante as revoluções modernas, como a Revolução Francesa (1789), no caso do capitalismo, é justamente a Escola que assume este papel. $\mathrm{O}$ aparelho ideológico escolar, neste sentido, assumiu uma posição dominante nas formas capitalistas maduras, encarregando-se das crianças de todas as classes no sentido de inculcar os saberes contidos na classe dominante ou simplesmente a ideologia dominante em estado puro para que estas ocupem na sociedade o papel que lhe convém.

Um dos principais atributos deste processo de inculcação, por sua vez, é o modo pelo qual os mecanismos que reproduzem esse resultado vital são naturalmente encobertos e dissimulados como neutros, destituídos de qualquer relação com interesses ou condições sociais mais específicas. Ela e o conteúdo de classe que repercute assumem, portanto, a forma 
própria da ideologia dominante, que é a de não ter uma história: seus agentes, os professores, diretores e técnicos, são projetados como detentores respeitosos da consciência e do senso de liberdade e moralidade. Seus conteúdos, não são outra coisa que não a representação viva da excelência e da verdade, absoluta aos olhos dos que a incorporam como tal.

A ideologia, portanto, na forma como é garantida pelos aparelhos ideológicos de Estado e pela superestrutura de um modo geral, é marcada por dois traços fundamentais. Primeiramente, ela representa a relação imaginária dos indivíduos com suas condições reais de existência, e sobretudo no que diz respeito à instituição escolar, que leva o indivíduo, por exemplo, a ver como equivalentes a qualificação que ele agrega à sua força de trabalho à quantificação da sua força de trabalho através do salário, o que esconde dele a concreticidade da exploração e o instituto da mais valia. Algo que se dá na medida em que ela mantém a existência de um pequeno grupo, responsável por manter a dominação de classe través de uma representação falseada do mundo, e ademais, na medida em que esta ideologia é a representação de uma realidade ou sociedade que é já, por si mesma alienada, fundada sob a égide de um trabalho ou de uma ação do mundo por parte do indivíduo desde já alienada de si mesma.

\section{CONSIDERAÇÕES FINAIS}

O universo de reflexões sobre as desigualdades educacionais o seu papel nos países no centro da economia capitalista no contexto do pós Segunda Guerra tem um perfil bastante diverso. Entre os levantamentos estatísticos e surveys e as teorias da reprodução, como pudemos observar, há uma abordagem bastante distinta sobre as razões e o modo como o ensino básico e também o ensino superior vinham se expandindo tanto na Europa quanto nos EUA. Contudo, é possível observar também como há uma continuidade na tentativa de desmistificar missões, responsabilidades e projetos ideológicos de desenvolvimento socioeconômico e combate às desigualdades sociais depositados sob a mesma, elevando o debate não apenas no sentido de rever criticamente as contradições presentes nestes projetos, como também a partir da forma com que o próprio conhecimento veiculado nas instituições educacionais, vinculado a eles ou não, poderia ser revisto e socializado de maneira a potencializar o seu caráter emancipatório. Algo que, por sua vez, não só trouxe uma resposta rápida aos equívocos na visão sobre os sistemas educacionais neste período como terminou transcendendo este objeto para, em última instância, oferecer uma importante base sob a qual a Sociologia da Educação poderia se desenvolver anos mais tarde. 


\section{REFERÊNCIAS}

ALBUQUERQUE, José Augusto. Althusser, As Ideologias e As Instituições. In.: ALTHUSSER, Louis. Aparelhos ideológicos de Estado. Rio de Janeiro: Edições Graal, 1983.

ALTHUSSER, Louis. Aparelhos ideológicos de Estado. Rio de Janeiro: Edições Graal, 1983.

BAUDELOT, Christian. Todo se sabe, y nada cambia: las dinámicas de clase contra el conocimiento. In.: FRIGERIO, Graciela; Gabriela, DIKER (orgs.). Educar: saberes alterados. Buenos Aires: Estante editorial, 2010.

BOURDIEU, Pierre. A miséria do mundo. Petrópolis: Vozes, 1997.

O capital social - notas provisórias. In.: NOGUEIRA, Maria Alice; CATANI, Afrânio. Escritos de educação. Petrópolis: Vozes, 1998.

BOURDIEU, Pierre; PASSERON, Jean-Claude. A reprodução: elementos para uma teoria do sistema de ensino. Petrópolis: Vozes, 2008.

Os herdeiros. São Carlos: Editora da UFSC, 2013.

COLEMAN, James. Equality of Education Opportunity. Whashinton D.C.: U.S. Goverment Printing Office, 1966.

GIRARD Alain; BASTIDE Henri. La stratification sociale et la démocratisation de l'enseignement. Population, v. 18, n. 3, 1963, Liège, p. 435-472.

GIROUX. Henry. Teoría y resistencia en educación. México: Siglo Veintiuno Editores, 2004.

HIGGINS, Silvio Salej. Quarenta anos do Relatório Coleman: capital social e educação. Educação UNISINOS, São Leopoldo, v. 9, n. 2, p. 116-129, maio /ago. 2005.

NOGUEIRA, Cláudio Marques; NOGUEIRA, Maria Alice. A Sociologia da Educação de Pierre Bourdieu: limites e contribuições. Educação \& Sociedade, n. 87, abril, 2002.

NOGUEIRA, Maria Alice. A Sociologia da Educação do final dos anos 60/ início dos anos 70: o nascimento do paradigma da reprodução. Em Aberto. Brasília, v. 09, n.46, p. 49-58, 1990. 